\title{
Acidente Vascular Cerebral Hemorrágico Secundário à Ruptura de Aneurisma Micótico em Paciente com Endocardite Bacteriana por Estreptococo Gama-Hemolítico
}

\author{
Gisele Sampaio Silva ${ }^{1}$ \\ Rodrigo Meirelles Massaud ${ }^{2}$ \\ Pedro Araújo Sampaio ${ }^{2}$ \\ Marcelo Opperman ${ }^{3}$ \\ Ayrton Roberto Massaro ${ }^{4}$ \\ Henrique Ballalai Ferraz ${ }^{5}$ \\ Alberto Alain Gabbai ${ }^{6}$
}

\begin{abstract}
RESUM 0
Aneurismas micóticos intracranianos são complicações raras associadas à endocardite infecciosa. Relatamos o caso de uma paciente com endocardite bacteriana diagnosticada por ocasião da ruptura de um aneurisma micótico, levando à hemorragia intraparenquimatosa e subaracnóidea. Colonoscopia realizada para evidenciar local de entrada bacteriana detectou pólipo adenomatoso. A associação entre patologias colônicas e endocardite bacteriana por Streptococcus bovis é bem descrita na literatura. Discutiremos as opções terapêuticas em casos refratários à terapêutica antimicrobiana. Unitermos: Endocardite, aneurisma micótico, patologia colônica.
\end{abstract}

\section{Introdução}

A incidência de infecções metastáticas e eventos embólicos associados à endocardite infecciosa é geralmente considerada elevada. A maioria desses eventos, no entanto, não é diagnosticada por permanecer assintomática ${ }^{1}$. Aneurismas micóticos de origem cardioembólica foram mais comuns na era pré-antibiótica, sendo hoje considerados complicação pouco freqüente na prática clínica ${ }^{2}$. Os territórios arteriais geralmente acometidos são os da aorta abdominal, artéria femoral, mesentérica superior, extremidades superiores e das ilíacas. A ocorrência de aneurismas micóticos intracranianos em pacientes com endocardite infecciosa é rara $^{3}$. Relataremos o caso de uma paciente que teve endocardite bacteriana diagnosticada após hemorragia intraparenquimatosa associada à ruptura de um aneurisma micótico.

\section{Relato de caso}

Paciente de 56 anos, do sexo feminino, casada, natural e procedente de São Paulo, foi admitida no serviço de emergência do Hospital São Paulo por cefaléia e dificuldade de comunicação iniciadas há duas horas. A família referia dois picos febris no dia anterior e sopro cardíaco diagnosticado há 20 anos. Ao exame físico, a paciente estava em regular estado geral, hidratada, pálida, febril $\left(38^{\circ} \mathrm{C}\right)$, normotensa (PA de 130 x $95 \mathrm{mmHg}$ ) e apresentava sopro sistólico em

\footnotetext{
Médica Residente da Disciplina de Neurologia da Escola Paulista de Medicina - Unifesp.

Médico Residente da Disciplina de Neurologia da Escola Paulista de Medicina - Unifesp.

Médico Estagiário da Disciplina de Neurocirurgia da Escola Paulista de Medicina - Unifesp.

Doutor em Neurologia da Disciplina de Neurologia da Escola Paulista de Medicina - Unifesp.

Doutor em Neurologia e Chefe do Setor de Distúrbios do Movimento da Disciplina de Neurologia da Escola Paulista de Medicina - Unifesp. Professor Titular e Chefe da Disciplina de Neurologia da Escola Paulista de Medicina - Unifesp.
} 
foco mitral com irradiação para a axila. $\mathrm{O}$ exame neurológico revelou dificuldade em nomear objetos e cores, alexia sem agrafia, incapacidade de distinguir entre direita e esquerda, acalculia e hemianopsia temporal direita. Exames laboratoriais mostraram anemia, leucocitose e aumento de velocidade de hemossedimentação ( $\mathrm{Hb}=9,8, \mathrm{Ht}=30 \%$, leucograma $=15.400$ leucócitos e VHS = 103). Tomografia computadorizada de crânio (TC) realizada três horas após o início dos sintomas revelou lesão espontaneamente hiperdensa em região parieto-occipital esquerda, que não realçou após injeção de contraste e sangue nas cisternas da base (Figura 1). Hemoculturas (feitas em duas amostras) colhidas no dia da admissão hospitalar foram positivas para estreptococo gama-hemolítico. Ecocardiograma transtorácico mostrou espessamento do folheto anterior da valva mitral e insuficiência mitral moderada. Ecocardiograma transesofágico não visualizou vegetações valvares. Foi introduzida antibioticoterapia com penicilina cristalina e gentamicina. Ressonância magnética de crânio revelou hemorragia parenquimatosa parieto-occipito-temporal esquerda com área de edema e efeito expansivo caracterizado pelo apagamento de sulcos e cisternas (Figura 2). Angiografia digital revelou presença de aneurismas micóticos das artérias angular esquerda e frontal interna posterior direita (ramo da artéria cerebral anterior) (Figura 3). Colonoscopia detectou

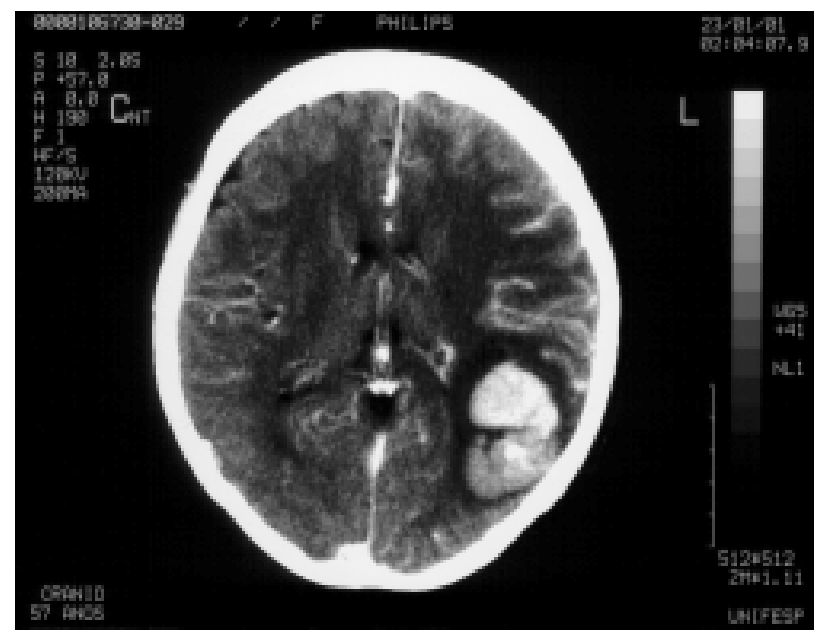

Figura 1 Tomografia computadorizada de crânio mostrando lesão espontaneamente hiperdensa em região parieto-occipital esquerda, sem realce significativo após injeção de contraste. Observa-se também presença de sangue nas cisternas da base, sugerindo extensão do sangramento ao espaço subaracnóideo.

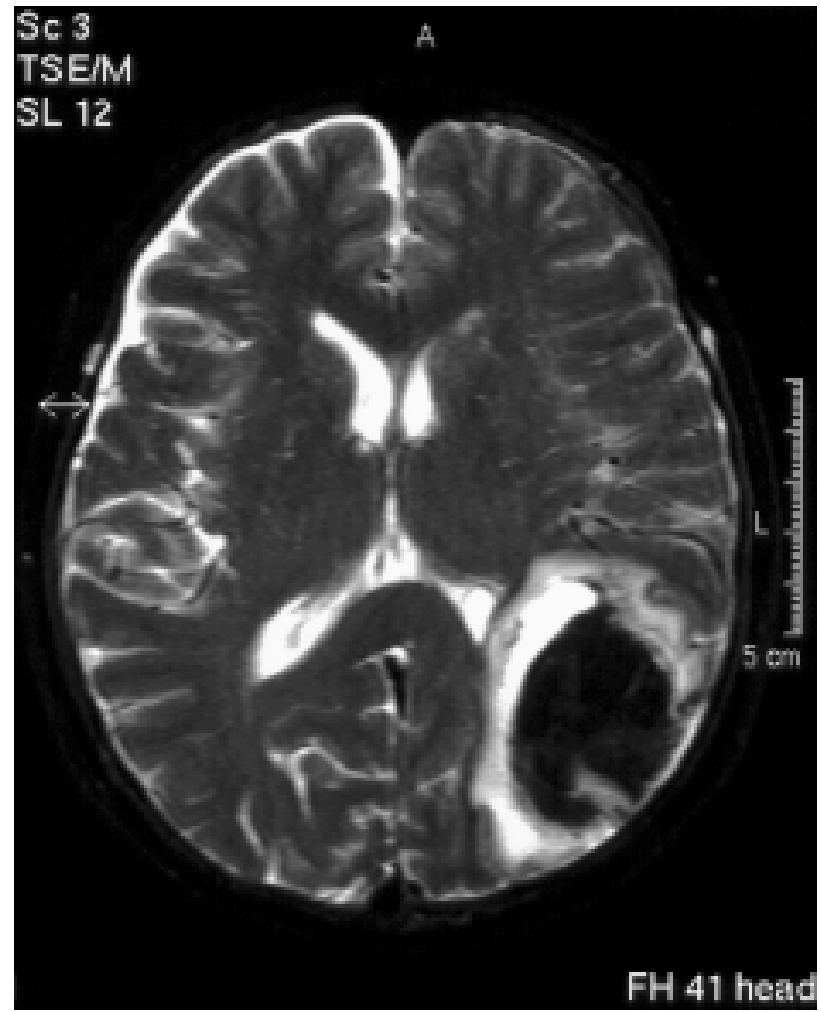

Figura 2 Ressonância nuclear magnética de crânio mostrando hemorragia parenquimatosa parieto-occipito-temporal esquerda, com área de edema e efeito expansivo caracterizado pelo apagamento de sulcos e cisternas. Observa-se, ainda, apagamento de sulcos corticais à esquerda com conteúdo sangüíneo em alguns sulcos corticais correspondendo à hemorragia subaracnóidea.

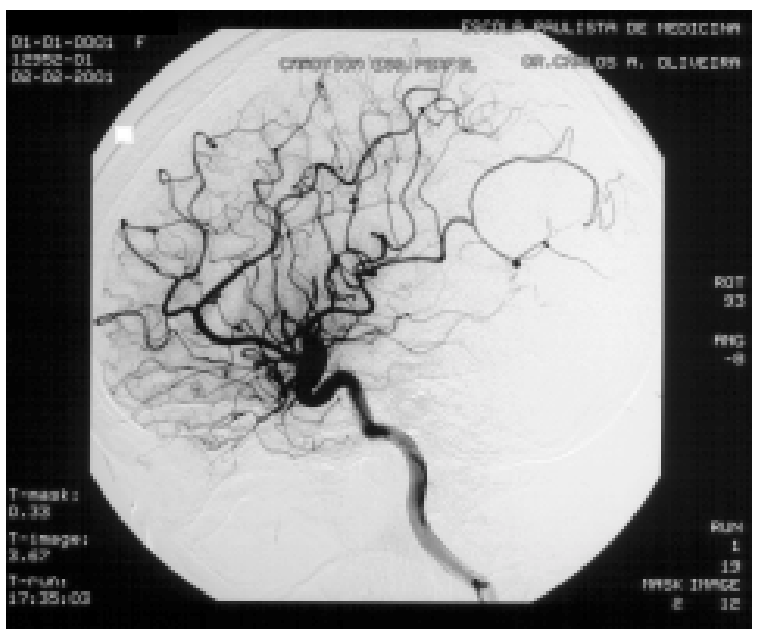

Figura 3 Angiografia cerebral mostrando área hipovascular parietal esquerda, notando-se desvio dos ramos da artéria angular, superior $e$ inferiormente, sugerindo hematoma intraparenquimatoso. Observa-se dilatação sacular localizada em ramo distal da artéria angular 
pólipo adenomatoso em cólon ascendente (realizada para investigar local de entrada bacteriana). A paciente permaneceu afebril após uma semana do início da antibioticoterapia, apresentando melhora do quadro neurológico. Nova angiografia realizada após seis semanas de tratamento revelou diminuição do tamanho do aneurisma fusiforme da artéria angular esquerda e nova lesão em artéria frontal interna posterior direita (Figura 4). Ecocardiograma transesofágico, realizado após o término do tratamento, mostrou presença de vegetação em resolução em valva mitral. Hemoculturas (feitas em três amostras) foram negativas. A paciente será submetida a procedimento cirúrgico valvar pela refratariedade ao tratamento antibioticoterápico.

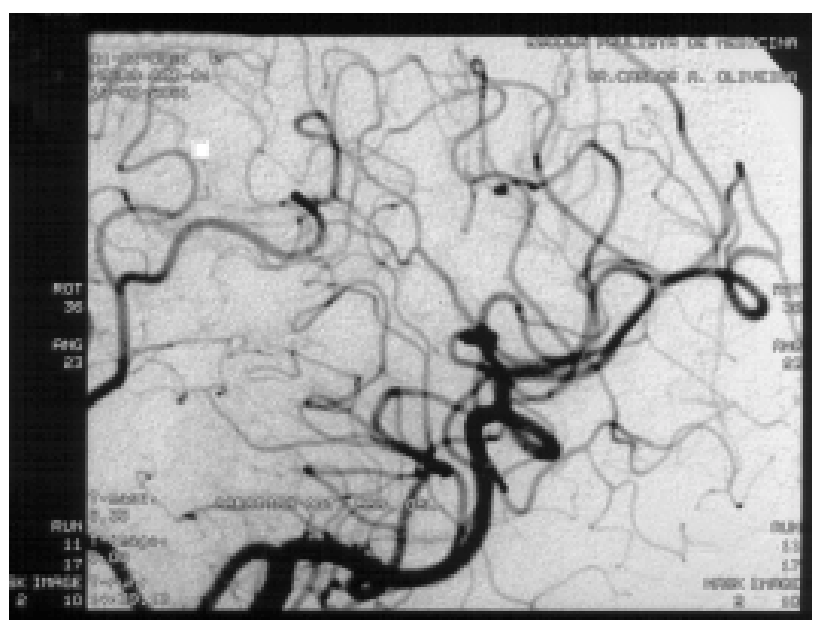

Figura 4 Angiografia cerebral mostrando duas pequenas dilatações saculares localizadas em ramos distais da artéria angular esquerda (a dilatação mais proximal já era observada no exame anterior e apresenta redução do seu tamanho). Nota-se, também, outra dilatação em ramo parietal anterior da artéria cerebral média esquerda. Presença de pequena dilatação sacular, em ramo frontal interno posterior da artéria cerebral anterior direita, que apresentou aumento de suas dimensões quando comparada com a do exame anterior.

\section{Discussão}

As bactérias causadoras de endocardite infecciosa podem colonizar outras áreas do sistema vascular, levando à destruição da parede do vaso e à formação de pseudo-aneurismas ${ }^{4}$. O termo aneurisma micótico foi utilizado por Osler, em 1885, para denominar essa complicação e, embora não seja apropriado, uma vez que não se trata de um aneurisma verdadeiro (não envolve todas as camadas da parede arterial), foi consagrado na literatura ${ }^{5}$. A incidência de aneurismas micóticos secundários à endocardite bacteriana tem diminuído bastante após a introdução de esquemas antibióticos de amplo espectro, sendo considerada rara na atualidade ${ }^{4}$. A formação de tais aneurismas parece dever-se à embolização de debris infectados para a vasavasorum com conseqüente formação de abscessos intramurais e isquemia da parede arterial, levando à degeneração de elementos musculares da artéria ${ }^{6}$. Em nosso caso, a paciente apresentou-se ao hospital por ruptura de um aneurisma micótico. A evolução clínica de hemorragias intraparenquimatosas e subaracnóideas secundárias à ruptura de aneurismas infecciosos costuma ser grave, com altos índices de mortalidade ${ }^{7}$. Nossa paciente evoluiu de maneira favorável, apresentando, na admissão, quadro clínico semelhante à síndrome de Gerstmann (dificuldade em diferenciar direita e esquerda, em nomear dígitos e em fazer cálculos) associada à alexia sem agrafia, permanecendo sem alterações do nível de consciência ${ }^{8}$. Aneurismas micóticos são mais comuns em endocardites subagudas causadas por bactérias menos virulentas, como os estreptococos, conforme observamos em nosso caso ${ }^{3}$. A associação entre endocardite por Streptococcus bovis e carcinoma de cólon é bem reconhecida, no entanto a presença de pólipos adenomatosos não é descrita como fator de risco para o desenvolvimento de endocardite por tal bactéria ${ }^{9}$. O tratamento de tais lesões é questão bastante controversa na literatura. A localização do aneurisma, o status cardíaco do paciente e a resposta à antibioticoterapia são fatores que devem ser considerados na decisão terapêutica ${ }^{10}$. O tratamento cirúrgico é geralmente reservado para lesões que sangram, sendo a abordagem de lesões assintomáticas geralmente contra-indicada ${ }^{3}$. A opção por manter acompanhamento radiológico, apesar das novas lesões observadas na angiografia, baseou-se no excelente estado geral da paciente, podendo tais aneurismas serem considerados assintomáticos. A abordagem cirúrgica da lesão valvar é consenso na literatura em casos considerados refratários a tratamento antibiótico ${ }^{1}$.

A existência da associação entre endocardite por Streptococcus bovis, uma espécie gama-hemolítica, e patologias colônicas não malignas (pólipos) pode ser questionada a partir da descrição desse caso, uma vez que tal associação é forte em se tratando de câncer de cólon. A terapêutica dos aneurismas micóticos persiste como assunto controverso na literatura, sendo este caso ilustrativo de que a conduta deve basear-se em um conjunto de fatores (localização, sintomas e agente etiológico), devendo sempre ser levada em consideração a evolução clínica do paciente. 


\section{SUMMARY}

Hemorragic cerebrovascular accident in a pacient with bacterial endocarditis and mycotic aneurysms

Mycotic aneurysms are major life threatening complications of infective endocarditis. We present a patient with a bacterial intracranial aneurysm refractory to antibiotics. The pathogenesis and therapeutic options are discussed. The management of cerebral mycotic aneurysms remains a controversal issue and factors as patient's cardiac status, the aneurysm's location and response to antibiotic therapy must be considered in the treatment of these lesions.

\section{Keyw ords}

Mycotic aneurysm, endocarditis, colonic disease.

\section{Referências}

1. Millaire A. Incidence and prognosis of embolic events and metastatic infections in infective endocarditis. European Heart Journal, 18:677-84,1997.

2. Mertens R. Aneurismas micóticos y embolías múltiples en una paciente con endocarditis infecciosa. Rev Méd Chile, 125:696-700, 1997.
3. Pruitt A. Neurologic complications of bacterial endocarditis. Medicine, 57(4):329-43,1978.

4. Osler W. The goulstonian lectures on malignant endocarditis. BMJ, 1:467-70,1985.

5. Jhirad R. Mycotic axillary artery aneurysm. Journal of Vascular Surgery, 28:708-9,1998.

6. Weinstein L. Life-threatening complications of infective endocarditis and their management. Arch Intern Med, 146:953-7,1986.

7. Salgado A. Neurologic complications of endocarditis: a 12-year experience. Neurology, 39:173-8,1989.

8. Caplan L. Cueing and memory dysfunction in alexia without agraphia. Brain, 97:251-62,1974.

9. Zarkin BA. The triad of Streptococcus bovis bacteremia, colonic pathology and liver disease. Ann Surgery, 211:78691, 1990.

10. Fizzell T. Treatment of a bacterial intracranial aneurysm using an endovascular approach. Neurosurgery, 32:8524,1993 . 